\title{
Pomza İlaveli Duvar Karolarının Ultrasonik Karakterizasyonunun Faktöriyel Tasarım ile İncelenmesi
}

\author{
Zahide Bayer Öztürk ${ }^{1, *}$, Elif Eren ${ }^{2}$ \\ ${ }^{1}$ Nevşehir Üniversitesi, Metalürji ve Malzeme Mühendisliği Bölümü, 50300, Nevşehir \\ ${ }^{2}$ Nevşehir Üniversitesi, Seramik ve Cam Tasarımı Bölümü, 50800 Hacıbektaş-Nevşehir
}

\begin{abstract}
Özet
Seramik karo üretiminde hammaddelere, kullanılan donanım ve teknolojiye bağlı olarak üretim sürecini etkileyen pek çok faktör bulunmaktadır. Nihai ürünün istenilen yoğunluk ve mukavemete ulaşması her aşamada yapılacak uygun düzenlemelerle mümkündür. Seramik karoların kalite kontrolünde yoğunluk, su emme ve mukavemet ölçüm testleri yaygın olarak kullanılmaktadır. Bu ölçümlere ilave olarak üretime anında müdahale edebilmesi ve daha kısa sürede daha çok ürün incelenebilmesi 'ultrasonik test yöntemi’ ile mümkün olmaktadır. Bu çalışmada duvar karolarının içerdiği pomza miktarlarının ve sinterleme sıcaklığının değişiminin ultrasonik özellikler üzer ${ }^{\dagger}$ ine olan etkisi faktöriyel deney tasarımı yöntemi kullanılarak incelenmiştir. Ultrasonik dalgaların ilerleme hızları, elastisite ve kayma modülleri, Poisson oranı üzerinde en etkin faktörler sinterleme sıcaklığı ve pomza miktarı olarak bulunmuştur. Etkileşim faktörünün ise incelenen özellikler üzerinde etkisi bulunmamaktadır. Ultrasonik dalgaların ilerleme hızı görünür gözenek miktarı ile ters orantılı değişmiş ve dalgaların ilerleme hızına bağlı olarak elastisite ve kayma modülleri ile Poisson oranları da değişim göstermişsir.
\end{abstract}

Anahtar Kelimeler: Duvar karosu, pomza, ultrasonik test, deney tasarımı.

\section{Ultrasonic Characterization of Pumice Added Wall Tiles with Factorial Design Analysis}

\begin{abstract}
The production of ceramic tiles is affected by many factors depending on the raw materials, equipment and technology used in the production process. To reach the desired density and strength of the final product can be made with suitable control arrangements at each stage. Density, water absorption and bending strength measurement tests are commonly used in the quality control of ceramic tiles. In addition to these measurements, controlling the production immediately and examining more products in less time is possible by 'ultrasonic testing method'. In this study, the effect of variation of pumice amount in wall tiles and sintering temperature on the ultrasonic properties were investigated using factorial experimental design. The sintering temperature and the amount of pumice were found to be the most effective factors on the velocity of ultrasonic waves, elasticity and shear modules, Poisson's ratio. Interaction factor has no effect on the investigated characteristics. The velocity of ultrasonic waves was inversely proportional with the apparent porosity and elasticity and shear modules, Poisson's ratio also changed depending on the velocity of ultrasonic waves.
\end{abstract}

Keywords: Wall tile, pumice, ultrasonic testing, experimental design.

*e-mail: z.ozturk@nevsehir.edu.tr 
Bayer-Öztürk Z., Eren E.

\section{Giriş}

Seramik karolar yer ve duvar kaplama malzemesi olarak kullanılan inorganik ürünlerdir. Duvar karoları diğer seramik karolara oranla daha yüksek gözenek miktarına ve daha yüksek su emme oranına sahip karolardır. Avrupa'da kabul edilen standartlara (EN 14411) göre su emmesi \%10'dan fazladır. Duvar karolarında genellikle karbonatlı hammaddeler (kil, kalsit vb.) kullanılmaktadır. Feldispatlar ve alkali içerikli hammaddeler az miktarda kullanılırlar [1]. Alkali içerikli hammaddelerden birisi de pomzadır. Dünyanın pek çok bölgesinde pomza yatakları bulunmasına rağmen, Türkiye en zengin ve kaliteli pomza yataklarına sahiptir [2]. Pomza, boşluklu, süngerimsi, volkanik olaylar neticesinde oluşmuş fiziksel ve kimyasal etkenlere karşı dayanıklı, gözenekli camsı volkanik bir kayaçtır [3]. Kimyasal bileşimi açısından \% 65-70 SiO ve düşük miktarda $\mathrm{TiO}_{2}$ ihtiva etmektedir [4].

Seramik karo üretiminde kalite kontrolü zor ve işgücü yoğun bir süreçtir. Bu süreçte geleneksel metotları kullanmak ve seramik üretiminde mikroyapı-hata gelişimini etkileyen farklı süreç değişkenlerinin etkisini en aza indirmek çok zordur [5]. Son yıllarda "tahribatsız muayene yöntemleri" malzemenin test sonrasındaki kullanımına zarar vermeden inceleme yapabilmesi ile daha etkin kullanılabilir hale gelmiştir [6]. Tahribatsız muayenenin ilk olarak üretim aşamasında kullanılması üretimin iyi yapılmasını, ikinci olarak üretimden sonra yapılması hatalı parçaların kullanım aşamasına geçmeden sınıflandırılmasııı sağlamaktadır [7].

Tahribatsız muayene tekniklerden birisi olan ultrasonik muayene yönteminde, malzemenin yüzeyindeki farklı bölgelere uygulanan yüksek frekanslı ses dalgalarının hareketi ölçülmektedir. Elektronik olarak kontrol edilebilen bu sinyaller, malzemede ilerledikten sonra akustik enerjinin tekrar elektronik sinyallere dönüştürülmesi ile toplanmaktadır. Tahribatsız muayene yönteminde genellikle 0,5$20 \mathrm{MHz}$ ultrasonik frekans aralığı kullanılmaktadır [8]. Ultrasonik dalgalar malzeme içinde ilerlerken malzemenin mikroyapısı ve mikroyapıdaki bölgesel farklılıklardan etkilenir. Bunun nedeni, ultrasonik dalgaların malzeme içindeki çatlak, gözenek gibi hacimsel hatalar, tane sınırları ve fazlar arası sınırlarla etkileşmesidir [9].

Ultrasonik metotlar seramiklerin mukavemetlerinin, gözeneklerinin ve malzeme içindeki hataların tespitinde uygulanabilmektedir. Ancak literatürde bu yöntemin seramiklerde kullanımına ilişkin yapılan az sayıda çalışma mevcuttur. Panakkal ve ark. [10], sinterlenmiş kil seramiklerin ve toz demir tabletlerin ultrasonik hızlarını elastisite ve kırılma teorileri ile kıyaslamalı olarak incelemiştir. Çalışmaları sonucunda yuvarlak şekilli olmayan gözeneklere sahip numunelerde büyük sapmaların elde edildiği tespit edilmiştir. Bhardwaj ve ark. [11] yaptıkları çalışmada ultrasonik yöntemle hataların tespit edilebilirliğini $14 \mathrm{~mm}$ kalınlığında ham porselene sinterlenmesi sonucunda ve \% 80 yoğunluğa ulaşmış $\mathrm{NaZr}_{2}(\mathrm{PO} 4)_{3}$ (NZP) seramiğine 1,5 mm çapında silindirik delikler açarak belirlemeye çalışmışlardır. Delik açılan seramiklerden elde edilen görüntüler benzerlik göstermiştir. Ultrasonik sinyallerin hatalı bölgeden geçişi esnasında, hatasız bölgeye göre iletilen enerji miktarının azaldığı tespit edilmiş̧ir [11, 12].

Deney tasarımı bir süreçteki girdi değişkenleri üzerinde istenilen değişikliklerin yapılmasıyla çıktı üzerindeki değişkenliğin gözlenmesi ve yorumlanması olarak tanımlanabilir [13]. Deney tasarım metotları ile üretim sırasında, kontrol edilemeyen faktörleri minimize ederek üretim sürecini tasarlamak mümkün olabilmektedir [14]. Bu çalışmada deney tasarım metotlarından tam faktöriyel tasarım 
uygulanmıştır. Bu tür deney tasarımında her bir faktörün seviyeleri için eşit sayıda tekrar yapılarak, faktörlerin diğer faktörlerden bağımsız olarak ürün performansı ya da sonuç üzerine etkileri belirlenebilmektedir [15].

$\mathrm{Bu}$ çalışmada duvar karosu reçetesine ilave edilen pomza miktarları ve sinterleme sıcaklıkları değiştirilerek sinterleme sonrası ultrasonik özellikler (boyuna ve enine ultrasonik hızlar, elastisite ve kayma modülleri, Poisson oranı) faktöriyel deney tasarımı kullanılarak incelenmiştir. Boyuna ve enine ultrasonik hızlar numunelerin görünür gözenek miktarlarıyla kıyaslamalı olarak incelenmiştir.

\section{Materyal ve Metot}

Deneylerde Nevşehir Denge Bims fabrikasından temin edilen asidik pomza kullanılmıştır. Pomza reçetelere $\% 7$ ve $\% 14$ oranlarında pegmatit hammaddesinin yerine ilave edilmiştir. Duvar karosu reçetesinde kullanılan hammaddelerin ve pomzanın kimyasal içeriği Çizelge 1'de verilmiştir. Bu çalışmada, pomzanın ergitici özelliği ve yüksek silis içeriği nedeniyle pegmatit yerine kullanımı incelenmiş̧ir. Reçetelerde değiş̧en hammadde miktarı Tablo 2'de verilmiştir. Reçetelere göre hazırlanan çamurlar etüvde kurutulduktan sonra, \%6 oranında nemlendirilerek $100 \mathrm{~mm}$ X $50 \mathrm{~mm}$ X $8 \mathrm{~mm}$ ebatlarında $450 \mathrm{~kg} / \mathrm{cm}^{2}$ basınçla tek eksenli presle şekillendirilmiştir. Faktöriyel tasarım metodunda deneyler için uygulanan faktörler ve seviyeleri Çizelge 3’te, her bir faktörün ana etkisi ve etkileşimi Tablo 4'de verilmiştir. Pomzanın miktarı 3 seviyeli (\% 0,\% 7, \% 14) ve sinterleme sıcaklığı 2 seviyeli $\left(1100{ }^{\circ} \mathrm{C}, 1150{ }^{\circ} \mathrm{C}\right)$ olarak belirlenmiştir. Deneyler iki tekrarlı olarak Minitab 14 istatistiksel paket programı ile tasarlanmış ve endüstriyel koşullarda sinterlenen karoların ultrasonik özelliklerinden boyuna ve enine dalga hızları, elastisite ve kayma modülleri analiz edilmiştir. Boyuna dalgalar incelenen malzemedeki taneciklerin titreşim hareketlerinin doğrultusunda ilerlerken, enine dalgalar malzemedeki taneciklerin titreşim hareketlerine dik doğrultuda ilerlerler. Bu nedenle aynı malzeme içinde boyuna dalgalar daha büyük yayılma hızına sahiptirler [16].

Numunelerde ultrasonik dalgaların ilerleme süresini ölçmek amacıyla Olympus Panametrics Model 5800 Computer Controlled Pulser/Receiver kullanılmıştır. Merkez frekansı $5 \mathrm{MHz}$ olan prob ultrasonik boyuna dalgaları numuneye iletmek, merkez frekansı 2,25 MHz olan prob ise ultrasonik enine dalgaları numuneye iletmek amacıyla cihaza bağlanmıştır. Numunelerin problarla incelenmesi sonucunda oluşan ultrasonik sinyallerden dalga ilerleme süresi ölçümleri dijital bir osiloskopla (Tektronix TDS 1012 Two Channel Digital Storage Oscilloscope) gerçekleştirilmiştir. Malzeme boyunca ilerleyen ultrasonik dalgaların hızı (Eşitlik 1)'e göre hesaplanmıştır.

$V=\frac{2 x d}{t}$

Burada V: ultrasonik dalgaların hızı, d: karoların kalınlığı $(\mathrm{mm})$, t: ultrasonik dalgaların ilerleme süresidir (m/sn) [17].

Bir malzemede boyuna dalganın ilerleme hızı $\left(V_{c}\right)$, Eşitlik 2'de ve enine dalgaların ilerleme hızı $\left(\mathrm{V}_{\mathrm{s}}\right)$ Eşitlik 3'te verilmiş̧ir.

$V_{c}=\left(\frac{E(1-v)}{\rho(1+v)(1-2 v)}\right)^{1 / 2}$ 
Burada $V_{c}$ : boyuna dalga hızı, E: malzemenin elastisite modülü, v: Poisson oranı, $\rho$ : malzemenin yoğunluğu'dur.

$$
V_{s}=\left(\frac{E}{2 \rho(1+v)}\right)^{1 / 2}=\sqrt{\frac{G}{\rho}}
$$

Burada G kayma modülünü ifade etmektedir. Eşitlik 3’ten hareketle kayma modülü, elastisite modülü ve Poisson oranı arasındaki ilişki Eşitlik 4-5’te verilmiştir [18]. Eşitliklerden görüldüğü gibi bir malzemede enine ve boyna dalga hızlarını ölçerek o malzemenin elestisite ve kayma modüllerini, Poisson oranını tespit edebilmek mümkündür [19].

$$
\begin{gathered}
G=\frac{E}{2(1+v)} \\
v=\frac{0,5-\left(\frac{V_{s}}{V_{c}}\right)^{2}}{1-\left(\frac{V_{s}}{V_{c}}\right)^{2}}
\end{gathered}
$$

Ayrıca Arşimet prensibine göre görünür gözenek değerleri hesaplanmıştır (Eşitlik 6):

\% Görünür gözenek $=\frac{\left(m_{y}-m_{k}\right)}{\left(m_{y}-m_{s}\right)} \times 100$

Burada $\mathrm{m}_{\mathrm{k}}$ kuru numunenin ağırlı̆̆ı, $\mathrm{m}_{\mathrm{y}}$ su emmiş numunenin ağırlı̆̆ $1, \mathrm{~m}_{\mathrm{s}}$ numunenin sudaki

\begin{tabular}{|c|c|c|c|c|c|c|c|c|c|c|c|c|}
\hline Hammaddeler & $\mathrm{SiO}_{2}$ & $\mathrm{Al}_{2} \mathrm{O}_{3}$ & $\mathrm{Fe}_{2} \mathrm{O}_{3}$ & $\mathrm{CaO}$ & $\mathrm{MgO}$ & $\mathrm{Na}_{2} \mathrm{O}$ & $\mathrm{K}_{2} \mathrm{O}$ & $\mathrm{P}_{2} \mathrm{O}_{5}$ & $\mathrm{Cr}_{2} \mathrm{O}_{3}$ & $\mathrm{TiO}_{2}$ & $\mathrm{SO}_{3}$ & K.K. \\
\hline Kil & 61,04 & 26,47 & 0,44 & 0,23 & - & 0,28 & 0,16 & 0,17 & 0,09 & 0,74 & 0,27 & 10,04 \\
\hline Kaolin & 63,21 & 21,88 & 3,19 & 0,14 & 0,62 & - & 2,46 & 0,04 & - & 1,28 & 0,08 & 7,05 \\
\hline Pegmatit & 66,48 & 20,04 & 1,32 & 0,50 & 0,38 & 2,68 & 2,78 & 0,06 & - & 0,96 & 0,05 & 4,69 \\
\hline Kalsit & 0,33 & - & 0,22 & 56,32 & - & - & - & 0,02 & 0,07 & - & - & 43,02 \\
\hline Silis Kumu & 91,58 & 5,07 & 0,51 & 0,07 & 0,04 & 0,10 & 0,52 & - & - & 0,24 & - & 1,82 \\
\hline Pomza & 73,18 & 12,43 & 1,22 & 0,82 & 0,03 & 4,06 & 4,62 & - & - & 0,08 & - & 3,53 \\
\hline
\end{tabular}
ağırlığıdır. Ultrasonik dalga hızları görünür gözenek değerleri ile kıyaslanmıştır.

Tablo 1. Hammaddelerin kimyasal analiz sonuçları (\%)

Tablo 2. Reçetelerde kullanılan hammaddelerin miktarları

\begin{tabular}{lccc}
\hline Reçeteler & $\mathbf{1}$ & $\mathbf{2}$ & $\mathbf{3}$ \\
Kil & 35 & 35 & 35 \\
Kaolin & 35 & 35 & 35 \\
Kalsit & 6 & 6 & 6 \\
Pegmatit & 14 & 7 & - \\
Silis kumu & 10 & 10 & 10 \\
Pomza & - & 7 & 14 \\
\hline
\end{tabular}


Tablo 3. Tasarımın faktör ve seviyeleri

\begin{tabular}{lccc}
\hline Faktörler & Seviyeleri & $\mathbf{3}$ \\
& $\mathbf{1}$ & $\mathbf{2}$ & 14 \\
Pomza miktarı (ă̆.\%) & 0 & 7 & - \\
Sinterleme sıcaklı̆̆ $\left({ }^{\circ} \mathrm{C}\right)$ & 1100 & 1150 & \\
\hline
\end{tabular}

Tablo 4. Faktörlerin ana etkileri ve etkileşimi

\begin{tabular}{lc}
\hline Ana faktörler & Etkileşim faktörleri \\
Pomza miktarı (ağ.\%) & Pomza miktarı (ağ.\%)*Sinterleme sıcaklığı $\left({ }^{\circ} \mathrm{C}\right)$ \\
Sinterleme sıcaklı̆̆ $\left({ }^{\circ} \mathrm{C}\right)$ & \\
\hline
\end{tabular}

\section{Bulgular ve Tartışma}

$2^{1} \times 3^{1}$ tam faktörlü ve iki tekrarlı faktöriyel tasarıma göre 12 adet numunenin boyuna ve enine dalga hızları, elastisite ve kayma modülleri, Poisson oranları incelenmiştir. Faktörler ve etkileşimleri ANOVA tablosu ile incelenmiştir. ANOVA tablosu faktör seviyeleri arasındaki farklılığın ve etkileşimlerinin anlamlı olup olmadığının anlaşılmasını sağlamaktadır [15]. Tablo 5 'te ultrasonik boyuna dalga hızı için etkin faktörler gösterilmiştir. Tablodaki DF serbestlik derecesini, Seq SS hata kareler toplamını, MS hata karesini, F dağılımı ise faktör değişimleri arasındaki farklılığı tanımlamaktadır. Kurulan modelde faktörün $F$ değeri ne kadar büyük olursa o faktör çıktı üzerinde en etkindir. P değeri ise güven aralı̆̆ını göstermektedir. Deneyler \%95 güven aralığında yapıldığı için P değerinin 0,05 ’ten küçük olması gerekir. P değeri büyük olan faktörler ANOVA tablosunda yer alan hata terimine eklenir. Ultrasonik boyuna dalga hızı için ana etkiler grafiği Şekil 1'de verilmiştir. Sinterleme sıcaklığının ve pomza miktarının (\%7'den \%14'e) artması ultrasonik boyuna dalga hızını arttırmıştır. Ultrasonik boyuna dalga hızı üzerinde sinterleme sıcaklığ $\% 83,5$ ve pomza $\% 10$ oranında etkin olup toplam etkilerin \%93,5'ini oluşturmaktadır (Şekil 2).

Tablo 5. Ultrasonik boyuna dalga hızı için ANOVA Tablosu

\begin{tabular}{lccccc}
\hline Faktörler & DF & Seq SS & MS & F & P \\
Pomza miktarı & 2 & 77003 & 38502 & 6,17 & 0,024 \\
Sinterleme sıcaklığ & 1 & 640332 & 640332 & 102,58 & 0,000 \\
Hata & 8 & 49936 & 6242 & - & - \\
Toplam & 11 & 767272 & - & - & - \\
\hline
\end{tabular}


Bayer-Öztürk Z., Eren E.

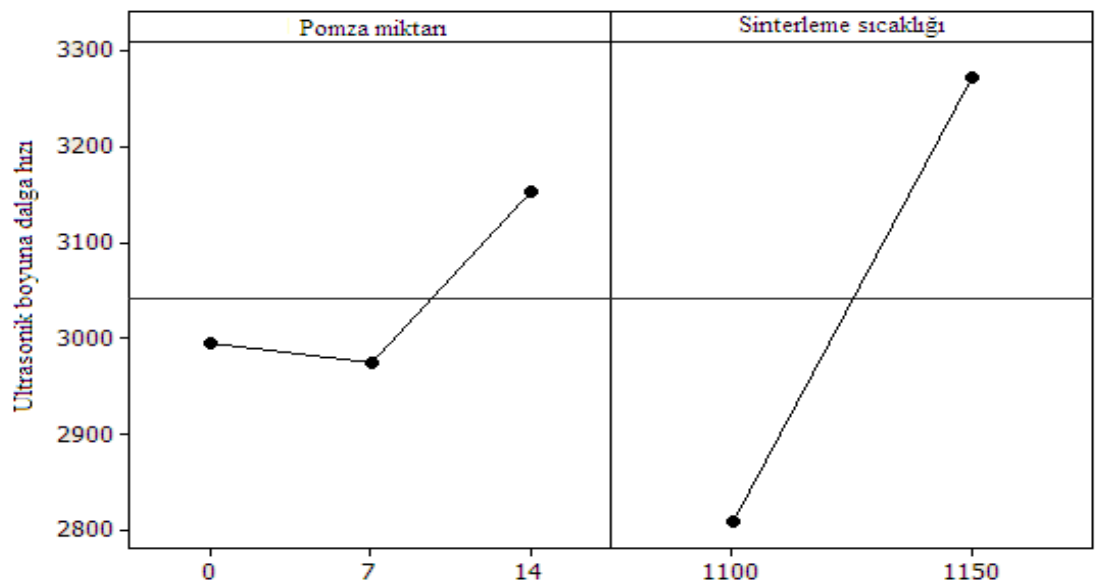

Şekil 1. Ultrasonik boyuna dalga hızı için ana etkiler grafiği

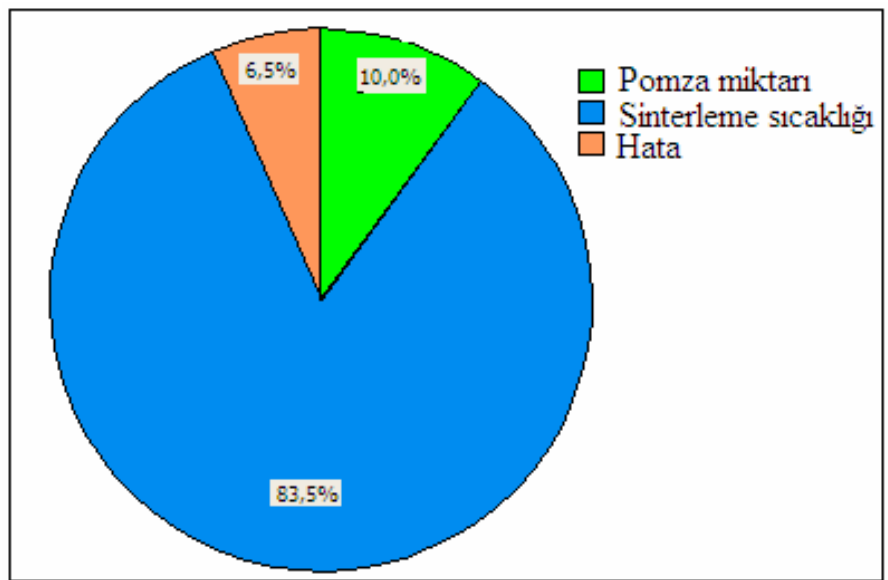

Şekil 2. Ultrasonik boyuna dalga hızı için pasta grafiği

Ultrasonik enine dalga hızı için sinterleme sıcaklığı $\% 71,2$ ve pomza miktarı $\% 20,1$ oranında etkin olup, toplam etkilerin \%91,3'ünü oluşturmaktadır. Tablo 6'da verilen ANOVA tablosunda da sinterleme sıcaklığının etkin olduğu ve artışı ile ultrasonik enine dalga hızının arttığı görülmektedir (Şekil $3)$.

Tablo 6. Ultrasonik enine dalga hızı için ANOVA Tablosu

\begin{tabular}{lccccc}
\hline Faktörler & DF & Seq SS & MS & F & P \\
Pomza miktarı & 2 & 53111 & 26556 & 9,24 & 0,008 \\
Sinterleme sıcaklığı & 1 & 188000 & 188000 & 65,39 & 0,000 \\
Hata & 8 & 23002 & 2875 & - & - \\
Toplam & 11 & 264114 & - & - & - \\
\hline
\end{tabular}


Nevşehir Bilim ve Teknoloji Dergisi Cilt 2(2) 135-145 2013

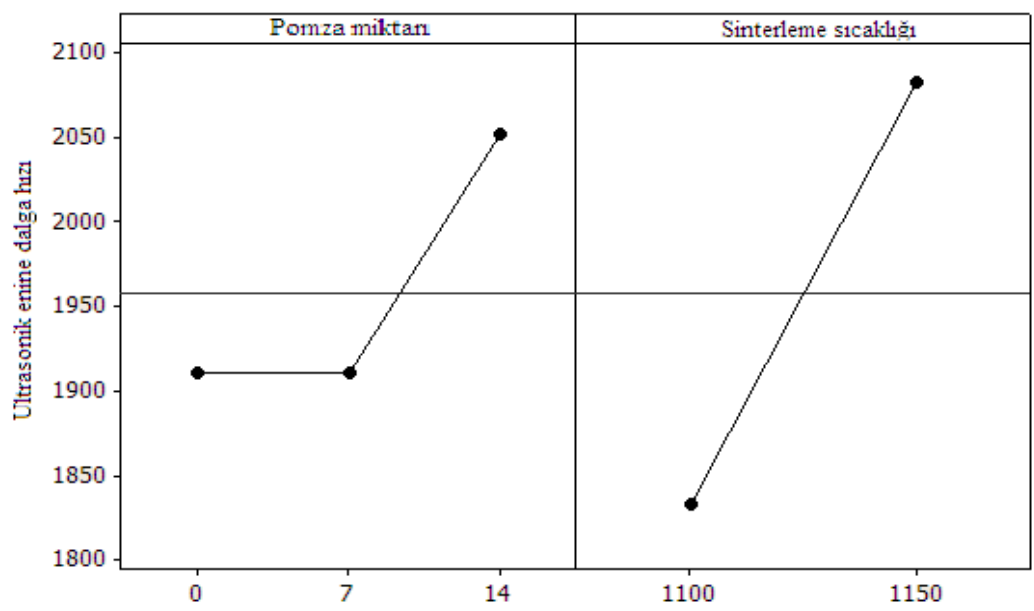

Şekil 3. Ultrasonik enine dalga hızı için ana etkiler grafiği

Elastisite modülü için sinterleme sıcaklığı \%76,3 ve pomza miktarı \%16,3 oranında etkin olup, toplam etkilerin \%92,6'sını oluşturmaktadır. Tablo 7'de verilen ANOVA tablosunda da en etkin faktörün sinterleme sıcaklığı olduğu, sinterleme sıcaklığı ve pomza miktarının artışı ile elastisite modülünün arttığı görülmektedir (Şekil 4). Güleç’in kayaçların fiziksel ve mekanik özelliklerinin su içeriğine bağlı değişimini incelediği çalışmasında, kayaçların çoğunun gözenekli ve çatlaklı yapısı nedeniyle su muhtevasının artması ile elastisite modülünün düştüğü tespit edilmiştir [20]. Seramik bünyelerde ise alkali ve toprak alkali ergiticiler ile vitrifikasyon erken başlamaktadır [21, 22]. Bu durumlar, pegmatitin yerine ilave edilen pomzanın alkali içeriğinin daha fazla olması ve sinterleme sıcaklığı artışının da etkisi ile daha yoğun ve gözenek miktarı daha düşük yapının oluştuğunu, bu yüzden elastisite modülünü arttırdığını düşündürmektedir.

Tablo 7. Elastisite modülü için ANOVA Tablosu

\begin{tabular}{lccccc}
\hline Faktörler & DF & Seq SS & MS & F & P \\
Pomza miktarı & 2 & 11,278 & 5,639 & 8,71 & 0,008 \\
Sinterleme sicaklığı & 1 & 52,920 & 52,920 & 81,71 & 0,000 \\
Hata & 8 & 5,181 & 0,648 & - & - \\
Toplam & 11 & 69,379 & - & - & -
\end{tabular}


Bayer-Öztürk Z., Eren E.

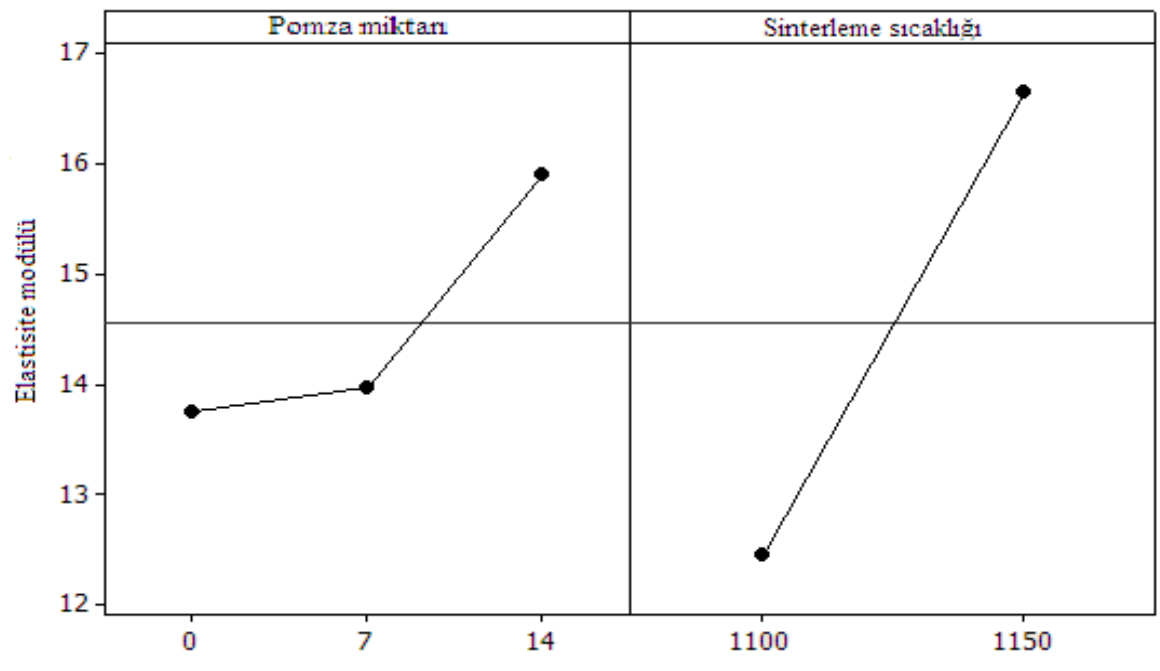

Şekil 4. Elastisite modülü için ana etkiler grafiği

Kayma modülü için sinterleme sıcaklığı $\% 68,6$ ve pomza miktarı $\% 22,8$ oranında etkin olup, toplam etkilerin \%91,4'ünü oluşturmaktadır. Tablo 8'de kayma modülü için ANOVA Tablosu verilmiştir. Şekil 5 'te verilen ana etkiler grafiğinde pomza miktarının ve sinterleme sıcaklığının artışının kayma modülünü arttırdığı görülmektedir.

Tablo 8. Kayma modülü için ANOVA Tablosu

\begin{tabular}{lccccc}
\hline Faktörler & DF & Seq SS & MS & F & P \\
Pomza miktarı & 2 & 2,9252 & 14626 & 10,58 & 0,006 \\
Sinterleme sicaklı̆̆ı & 1 & 8,8100 & 8,8100 & 63,75 & 0,000 \\
Hata & 8 & 1,1056 & 0,1382 & - & - \\
Toplam & 11 & 12,8407 & - & - & - \\
\hline
\end{tabular}

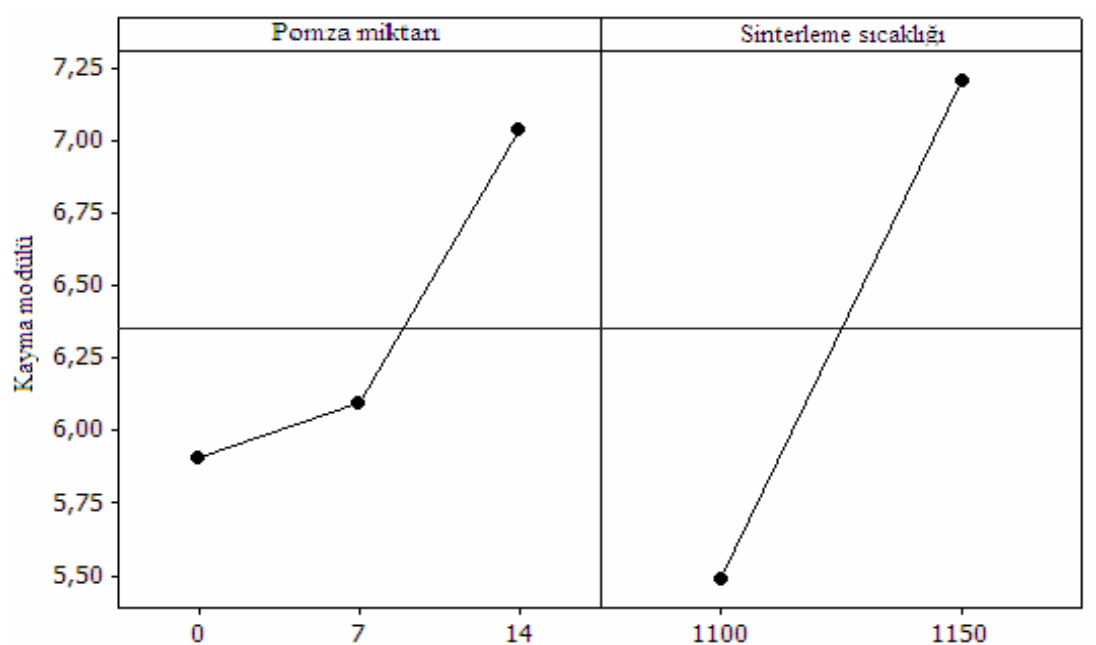

Şekil 5. Kayma modülü için ana etkiler grafiği 
Poisson oranı için pomza miktarı \%42 ve sinterleme sıcaklığg $\% 24,4$ oranında etkin olup, toplam etkilerin \%66,4'ünü oluşturmaktadır. \%33,6 hata oran1, Poisson oranı için kontrol edilemeyen faktörlerin etkisinin fazla olduğunu göstermektedir. Tablo 9'da Poisson oranı için ANOVA Tablosu, Şekil 6'da ana etkiler grafiği verilmiştir.

Tablo 9. Poisson oranı için ANOVA Tablosu

\begin{tabular}{llllll}
\hline Faktörler & DF & Seq SS & MS & F & P \\
Pomza miktarı & 2 & 0,0023472 & 0,0011736 & 4,99 & 0,039 \\
Sinterleme sıcaklığı & 1 & 0,0013653 & 0,0013653 & 5,81 & 0,043 \\
Hata & 8 & 0,0018812 & 0,0002351 & - & - \\
Toplam & 11 & 0,0055937 & - & - & - \\
\hline
\end{tabular}

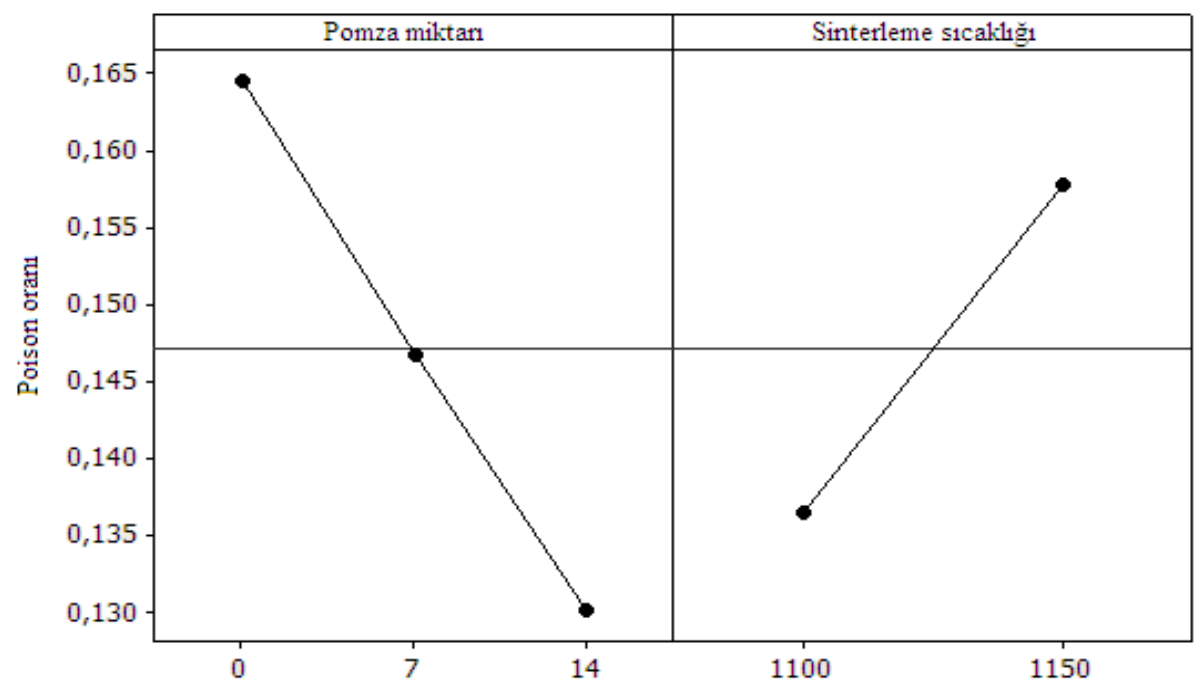

Şekil 6. Poisson oranı için ana etkiler grafiği

İki tekrarlı olarak incelenen numunelerin pomza miktarının ve sinterleme sıcaklığının artışı ile \% görünür gözenek değerlerinin düştüğü tespit edilmiştir (Tablo 10).

Tablo 10. Numunelerin \% görünür gözenek değerleri

\begin{tabular}{ccc}
\hline Pomza miktarı (ă̆.\%) & Sinterleme Sicaklı̆̆ $\left({ }^{\circ} \mathrm{C}\right)$ & \% Görünür gözenek \\
0 & 1100 & 39,$62 ; 40,48$ \\
0 & 1150 & 38,$53 ; 37,10$ \\
7 & 1100 & 36,$04 ; 35,87$ \\
7 & 1150 & 36,$02 ; 35,78$ \\
14 & 1100 & 35,$67 ; 36,13$ \\
14 & 1150 & 35,$35 ; 35,17$ \\
\hline
\end{tabular}


İçsel bir hava boşluğu etrafında bir dalganın saçılımı ultrasonik hızın azalmasına yol açacaktır [23]. Pomza miktarının ve sinterleme sıcaklığının artması ile azalan görünür gözenek değerleri numunelerde ultrasonik enine ve boyuna dalga hızlarının, dalga saçılımındaki azalmaya bağlı olarak arttığı belirlenmiştir.

\section{Sonuç}

Pomza miktarı ve sinterleme sıcaklığı değiştirilen duvar karolarında ultrasonik test yöntemi ile boyuna ve enine dalga hızı ölçümleri ve bunlara bağlı elastisite ve kayma modülleri, Poisson oranı değerleri ölçülmüş olup $2^{1} 3^{1}$ tam faktöriyel tasarıma göre iki tekrarlı olarak incelenmiştir. Yapılan faktöriyel tasarımda ultrasonik dalgaların ilerleme hızı (enine ve boyuna), elastisite modülü, kayma modülü ile pomza miktarı ve sinterleme sıcaklığı faktörlerinin doğru orantılı değişim gösterdiği tespit edilmiştir. Ultrasonik özellikler üzerinde pomza miktarı*sinterleme sıcaklı̆̆ı etkileşim faktörünün etkisi olmadığı tespit edilmiştir.

Malzemede dalgaların ilerlemesini engelleyecek gözenek miktarına bağlı olarak, dalgalar daha yavaş hızda ilerleme göstereceğinden numunelerin görünür gözenek miktarları da incelenmiştir. Pomza miktarının ve sinterleme sıcaklığının artışı ile gözenek değerlerinin düştüğü ve buna bağlı olarak ultrasonik dalgaların ilerleme hızının arttığı düşünülmektedir.

\section{Kaynaklar}

[1] Endüstriyel Hammaddeler Alt Komisyonu Toprak Sanayi Hammaddeleri (Seramik killeri, kaolen, feldispat, profillit, wollastonit, talk) Çalışma Grubu Raporu, DPT Sekizinci Beş Yıllık Kalkınma Plan1, Ankara, 2001 http:// www. ekutup.dpt.gov.tr/madencil/sanayiha/oik622.pdf

[2] Civan L., “ Pomzanın Sır Bileșeni Olarak Kullanılması ve İncelenmesi”, Anadolu Üniversitesi, Fen Bilimleri Enstitüsü, Yüksek Lisans Tezi, Eskișehir, 2011

[3] Çayırlı S., “Farklı Tür Pomzaların Kesikli Ögütme Ortamındaki Davranışlarının İncelenmesi ve Modellenmesi”, Süleyman Demirel Üniversitesi, Fen Bilimleri Enstitüsü, Yüksek Lisans Tezi, 96s, Isparta, 2008

[4] Çimento Hammaddeleri ve Yapı Maddeleri, 7. Beş Yıllık Kalkınma Planı Özel İhtisas Komisyon Raporu, Cilt 1-2-3, DPT, Ankara, $1996 \quad$ http:/l www. ekutup.dpt.gov.tr/madencil/sanayiha/oik491c1.pdf.

[5] Shilling C.H., Gray J.N., “ Needs and Opportunities for NDE in Ceramic Processing, Ceramic Transactions", Westerville, 1-19s, A.B.D., 1997

[6] Elbehiery H.M., Hefnawy A.A., Elewa M.T., "Quality Control Enhancement via NonDestructive Testing for Green Ceramic Tiles", 46 th IEEE International Midwest Symposium on Circuits and Systems, Proceedings book, 1130-1133, 2003

[7] Arnold W., Reither H., “ Nondestructive Testing of Ceramic Engineering Components by X-ray and Ultrasonic Techniques", Advances Ceramics: Proceedings of an International Symposium on Advanced Ceramics (Ed: Ganguly, G., Roy, S.K., Roy, P.R.), Trans Tech Publications, 56-57, 393-410s, İsviçre, 1991 
[8] Grandt Jr., A.F., "Fundamentals of Structural Integrity Damage Tolerant Design and Nondestructive Evaluation”, John Wiley \& Sons, Inc., New Jersey, A.B.D., 2004

[9] Gür C.H., "Tahribatsız Tekniklerin Malzeme Özelliklerinin Belirlenmesindeki Yeri”, 1. Uluslar arası Tahribatsı Muayene Sempozyumu ve Sergisi, Bildiriler Kitabı, Türkiye Mühendis ve Mimarlar Odası Birliği Metalurji Mühendisleri Odası, 357-372s, Ankara, 1999

[10] Panakkal J.P., Willems H., Arnold W., “ Nondestructive Evaluation of Elastic Parameters of Sintered Iron Powder Compacts”, Journal of Materials Science, 25, 1397-1402s, 1990

[11] Bhardwaj M.C., Neeson I., Stead G., "Introduction to Contact-free Ultrasonic Characterization and Analysis of Consolidated Materials", NDTnet, 5, 2000.

[12] Eren E., Kurama S., "Using Ultrasonic Test Method for Porosity Characterization of Porcelain Bodies”, ICCPS-11 International Conference on Ceramic Processing Science, Abstract Booklet, 195, Zurich, İsviçre, 2010

[13] Besterfield D.H., Besterfield C., Besterfield G.H., Besterfield M., “Total Quality Management”, Prentice Hall Inc., New Jersey, 1995

[14] Taylan D., "Taguchi Deney Tasarımı Uygulaması”, Süleyman Demirel Üniversitesi, Fen Bilimleri Enstitüsü, Yüksek Lisans Tezi, 73s, Isparta, 2009

[15] Montgomery D.C., "Design and Analysis of Experiments" 5th ed., John Wiley \& Sons, New York, 2001.

[16] Yüksel M., Meran C., "Malzeme Bilgisine Giriş”, Makine Mühendisleri Odasl, Cilt 2, Yayın No MMO/545, 2010

[17] Medding J.A., "Nondestructive Evaluation of Zirconium Phosphate Bonded Silicon Radomes", Fen Bilimleri Enstitüsü, Yüksek Lisans Tezi, Virginia Polytechnic Institute and State University, Virginia, 1996.

[18] http://kursatozcan.com/ders_notlari/f_bayram_kayac_mekanigi.pdf.

[19] http://www.muhfak.ktu.edu.tr/metalurji/lab_foyler/ultrasonik\%20muayene.pdf) mmo.org.tr/resimler/dosya_ekler/d73e7e7ec54f8ac_ek.pdf?dergi=768.

[20] http://www.maden.org.tr/resimler/ekler/66d856ef1a6b02f_ek.pdf.

[21] Aras A., ve Demirhan H., "Firing Behaviour of Alkaline Earth Flux in Ceramic Bodies: The Effect of Magnesite on Firing Mineralogy and Physical Properties”, Key Engineering Materials, 264-268, 1523-1526s, 2004

[22] Kocabaş M.S., "Porselen Karo ve Anortit Minerali ile Geliştirilen Kompozisyona Magnezyumlu Kil ve/veya Handit İlavesinin Teknolojik Özellikler Üzerine Etkisi”, Gebze Yüksek Teknoloji Enstitüsü, Fen Bilimleri Enstitüsü, Yüksek Lisans Tezi, Gebze, 2007.

[23] Özçep F., Karabulut S., Özgüven B, Sanlı O., "Tahribatsız Test Yöntemleri ve Ultrasonik Hız Ölçümleri”, http://www.jeofizik.org.tr/resimler/ekler/76a0caeaa1b986b_ek.pdf?dergi=34. 